\title{
Gender differences in the prevalence of congenital heart disease in Down's syndrome: a brief meta-analysis
}

\author{
Tereza Cristina Pinheiro Diogenes ${ }^{1,2}$, Felipe Alves Mourato ${ }^{1,2,3^{*}}$ (D) José Luiz de Lima Filho ${ }^{2}$
} and Sandra da Silva Mattos ${ }^{1,2}$

\begin{abstract}
Background: Down's syndrome (DS) affects one per 700 live births and congenital heart disease (CHD) occurs in 40-60\% of these patients. Contributing factors to the association between DS and CHD are being unraveled. Gender could be one of them.

Methods: We performed a meta-analysis of CHD prevalence in DS, separated by gender. Three search engines were used and 578 articles were reviewed. Twelve articles were included.
\end{abstract}

Results: Quantitative analysis showed a higher prevalence of CHD, particularly atrioventricular septal defects (AVSD), in female patients. No differences were found in others forms of CHD.

Conclusion: CHD, particularly AVSD, are more common in the female gender of Down's syndrome patients.

Keywords: Down, Gender, Meta-analysis, Systematic review, Congenital heart disease

\section{Background}

Down's Syndrome (DS) affects one in each 700 live births $[1,2]$. Its incidence is directly related to maternal age and has been increasing throughout the world [3]. Congenital Heart Disease (CHD) occurs in $40-60 \%$ of DS cases [4] and constitutes an important prognostic factor in these patients. Numerous factors may contribute to the development of different cardiac malformations in DS. Some are being unraveled recently in animal models [5]. However, until now, there has been few reports looking into the association of gender with CHD and DS.

It is well known that DS is a risk factor for CHD. In these patients, the most frequent forms of CHD are atrioventricular septal defects (AVSD), ventricular septal defects (VSD) and atrial septal defects (ASD) [6, 7]. The reported prevalence of these defects varies among studies [8-14]. This could reflect inherent characteristics of the studied populations, such a higher frequency of genetic variances that predispose to the presence of AVSD [5, 15-19].

\footnotetext{
* Correspondence: felipe.a.mourato@gmail.com

${ }^{1}$ Círculo do Coração de Pernambuco, Recife, Pernambuco, Brazil

'Universidade Federal de Pernambuco (UFPE), Recife, Pernambuco, Brazil

Full list of author information is available at the end of the article
}

In this context, gender could influence the presence and type of CHD. Some studies point out a higher predominance of male gender in patients with DS [20,21], but studies carried out in pediatric cardiology centers point to a large number of female patients with DS and CHD [20, 22]. This paradox could be explained by a higher incidence of CHD in female patients with DS, leading to higher mortality rates earlier in life, although many other unknown factors could be at play to influence these findings.

The purpose of this study was to compare the prevalence of CHD and DS between genders through a metaanalysis and systematic review.

\section{Methods \\ Eligibility criteria}

Studies that described the prevalence of CHD in DS by gender were included. Studies where this information was not available were excluded.

\section{Information sources}

The search for articles was performed using the following data engines: Medline (accessed via Pubmed), Scopus and Scielo. Terms included were those used by Mesh for 


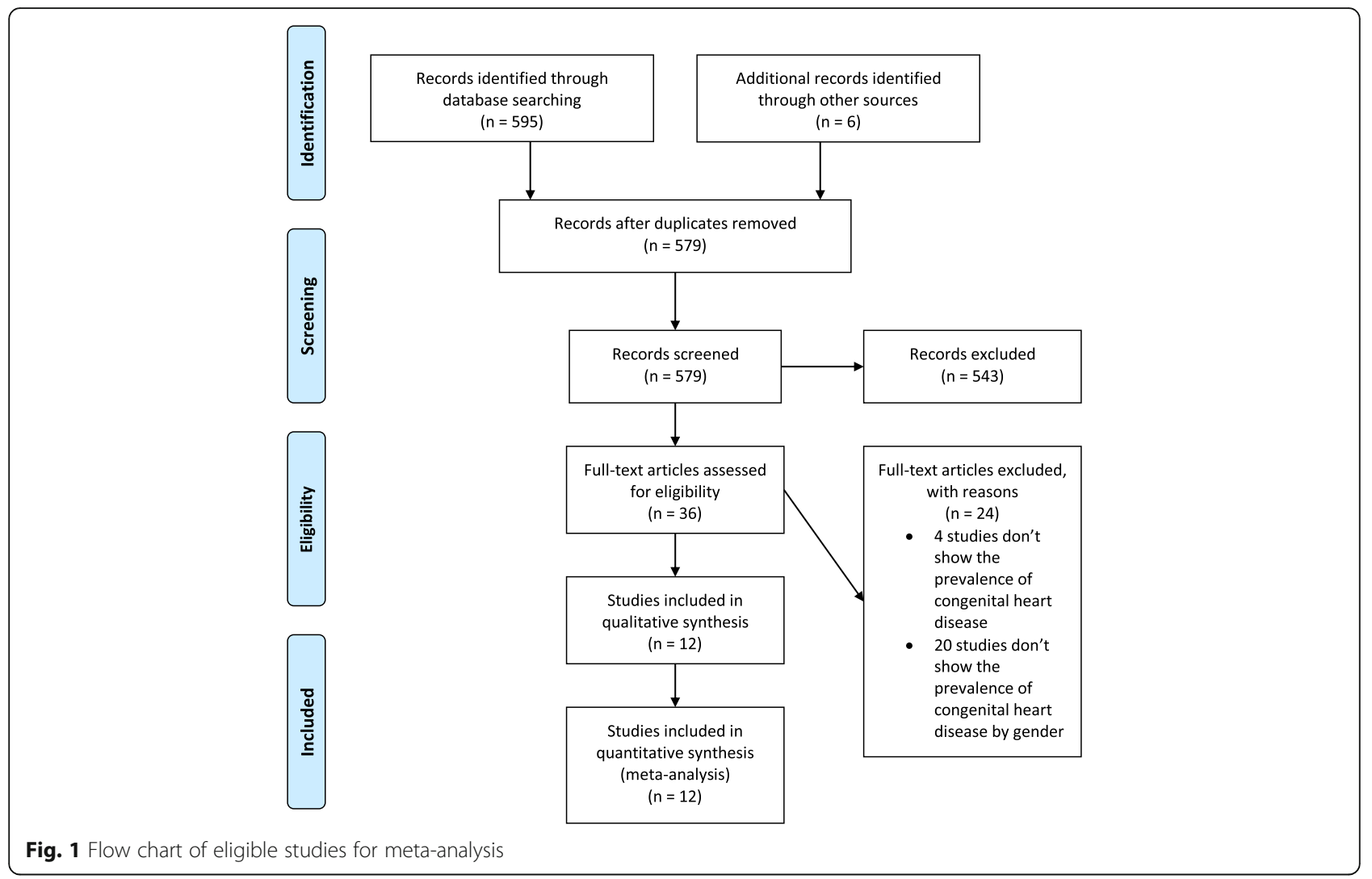

Medline and Scopus, and the descriptors of Health Sciences (Decs) for Scielo. Terms included: "prevalence", "Down syndrome" and "congenital heart disease". Additional file 1 contains the full search strategy. Articles, published until August 30th, 2016, were included. Additional search was performed in the bibliographic references of the researched articles. Authors from selected papers with incomplete data were contacted by e-mail. Complete articles were obtained and analyzed by authors.

\section{Selection of studies and data extraction}

Two authors (Mattos and Mourato) evaluated the title and abstracts of the identified articles. The complete texts of the selected abstracts were obtained and posteriorly analyzed by the same authors. After this initial analysis, each selected article's information were added to a database. The authors agreed that discordances about the inclusion of an article should be sorted by consensus. However, there were no disagreements. Duplicated studies were excluded.

\section{Data analysis}

Gender prevalence was calculated by dividing the total number of DS patients with CHD by the total number of DS for each gender. The prevalence of AVSD, ASD, VSD, PDA (patent ductus arteriosus) and TOF (tetralogy of Fallot) were calculated dividing the number of DS
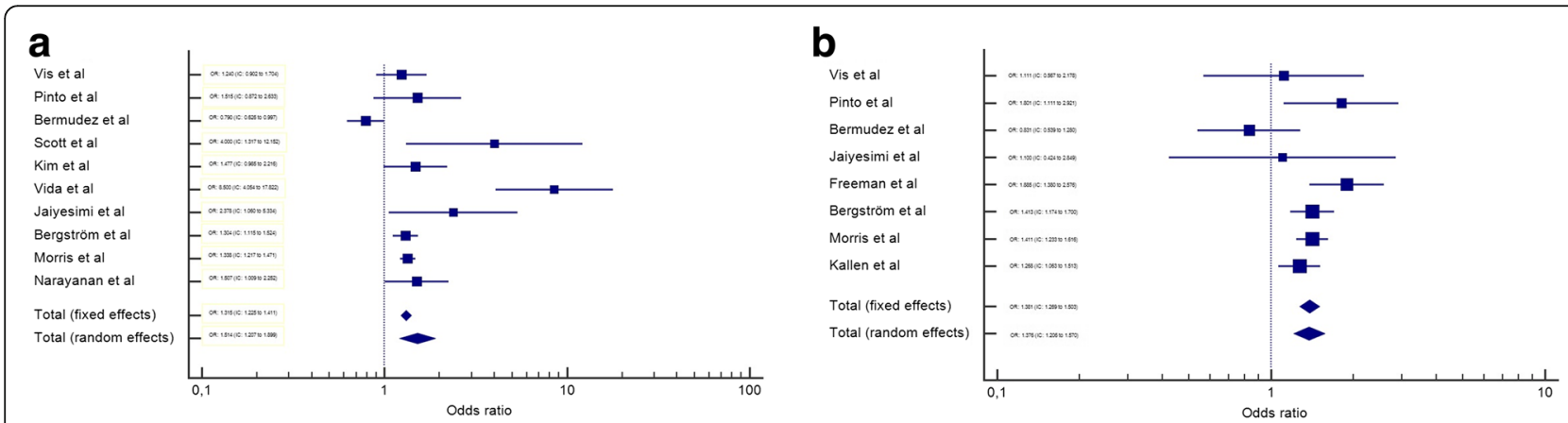

Fig. 2 Meta-analysis of all CHD and AVSD by gender in Down syndrome. IC-Interval of confidence. OR-Odds Ratio. a - OR meta-analysis of all CHD in Down syndrome by gender. $\mathbf{b}$ - OR meta-analysis of AVSD in Down syndrome by gender 

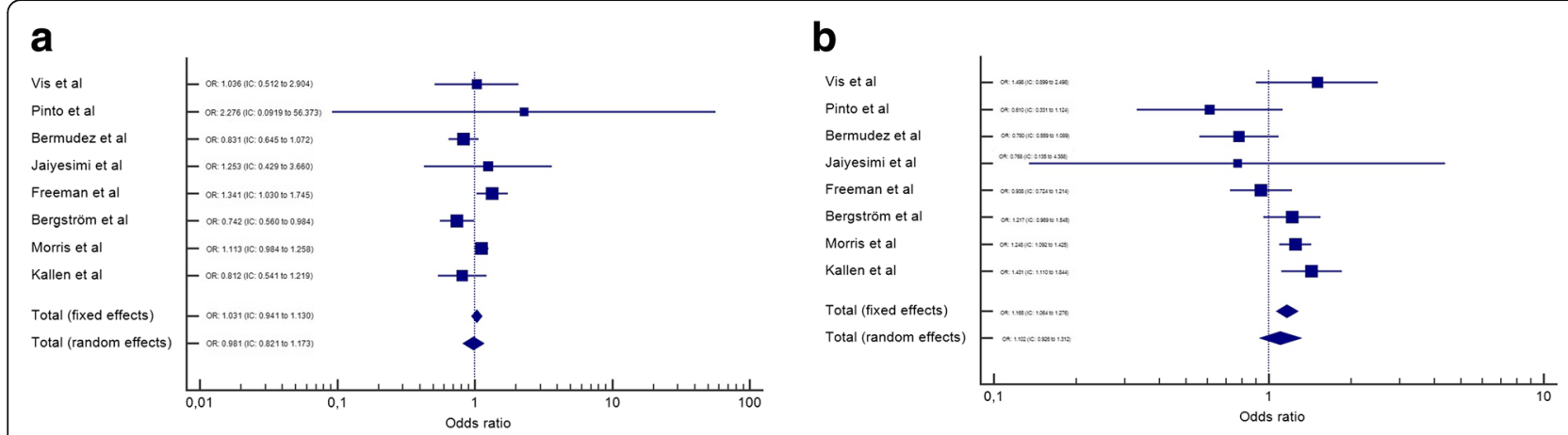

Fig. 3 Meta-analysis of ASD and VSD by gender in Down syndrome. IC-Interval of confidence. OR-Odds Ratio. a - OR meta-analysis of ASD in Down syndrome by gender. $\mathbf{b}$ - OR meta-analysis of VSD in Down syndrome by gender

with each cardiac defect by the total number of patients with DS in the study. A combined data analysis was performed to identify the Odds Ratio between genders, being the female gender considered a risk factor. The confidence intervals and the size of the pondered effect were calculated and the meta-analysis graphs built using the MedCalc v 16.8 software.

Heterogeneity between studies was calculated using the $\mathrm{I}^{2}$, which describes the variability, not related to sample errors, in the studied population. An $\mathrm{I}^{2}$ beyond $75 \%$ is consistent with high heterogeneity. As such, the meta-analysis should be carried out using the fixed model if the heterogeneity analysis resulted in number constantly inferior to $75 \%$ and using a random effects model if it resulted in a number equal or superior to $75 \%$ (i.e. considering the $\mathrm{I}^{2}$ confidence interval). The Mantel-Haenszel method was used for calculating the weighted summary Odds ratio under the fixed effects model. Subsequently, heterogeneity statistics were incorporated to calculate the summary Odds ratio under the random effects model (in accordance to $\mathrm{I}^{2}$ statistics).

\section{Results}

From the engine database sources, 595 abstracts were selected. Initial review identified 35 for full text analysis.
From this latter group, only four fulfilled the eligibility criteria and were included in the meta-analysis [22-25]. Direct contact with the authors of the remaining 31 articles made it possible to include another eight studies [12, 13, 20, 26-30], totalizing 12 articles for analysis. In total, 20,465 patients with DS (11,165 male and 9300 female) were included in the meta-analysis. Figure 1 demonstrates articles selection's process and progress, according to the PRISMA method. Raw data were included in the Additional file 2.

After the meta-analysis, it was observed that female gender is a risk factor for the presence of CHD in DS (Fig. 2). The same occurs if we consider AVSD alone (Fig. 2). However, when VSD, ASD, PDA and TOF (Figs. 3 and 4) are considered separately, there is no difference among genders. All analyses utilized the random effects' model.

\section{Discussion}

The frequency of CHD in this systematic analysis is in accordance with other studies involving DS $[8,10-12$, $14,20,24,28,31-35]$. Few studies fulfilled the inclusion criteria for this meta-analysis. The main problem was the lack of information about the prevalence of CHD in DS, according to gender. Some studies mentioned an association between the female gender and a higher
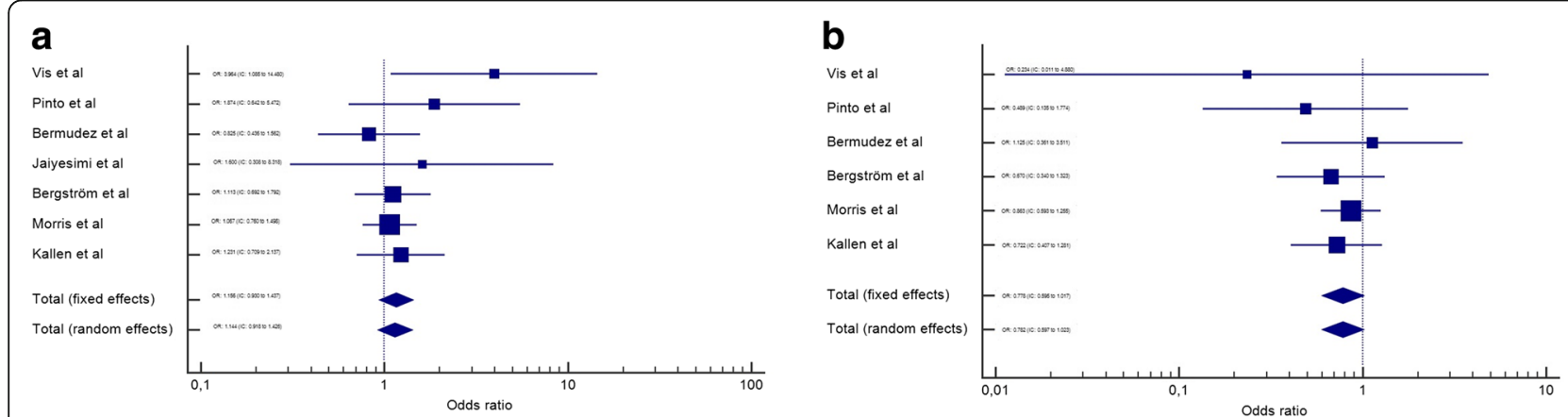

Fig. 4 Meta-analysis of PDA and TOF by gender in Down syndrome. IC-Interval of confidence. OR-Odds Ratio. a - OR meta-analysis of PDA in Down syndrome by gender. $\mathbf{b}$ - OR meta-analysis of TOF in Down syndrome by gender 
prevalence of CHD [20, 22]. However, these findings were not highlighted subsequently.

Various theories exist to explain the origins of CHD in DS. Some authors suggest that the presence of certain variants in specific genes could be the underlying cause for $\mathrm{CHD}$ in this population $[5,36]$. Others suggest a correlation with the presence of single nucleotides polymorphism (SNPs) and Copy Number Variations (CNVs) [18]. And there are also ethnical genetic differences, which could play a role in the different incidence of CHD among these patients $[20,24]$. In this context, differences between gender, with their specific genetic charges, could also exert an influence over the determining factors for CHD in this population.

In this meta-analysis, we observed a higher frequency of CHD in the female gender (OR: 1.514, IC: 1.207 to 1.899). This finding suggests that this gender is more susceptible to CHD in DS. Another finding that supports this conclusion is that AVSD, alone, also showed a higher frequency in female gender (OR: 1.376, IC: 1.206 to 1.570); and this form of CHD is more prevalent in DS than the general population [37]. TOF, on the other hand, was more frequent in males, but without statistical significance (OR: 0.782, IC: 0.597 to 1.023$)$. These differences might be explained by a potential different susceptibility of gender to different CHD pathogenic pathways (for example, AVSD is correlated with extracellular matrix anomalies and TOF with ectomesenquimal tissue migration anomalies [38]). Other possible explanation would be that males with DS die before birth or before the timing of these studies (with similar incidence early in life, but a lower prevalence later). Unfortunately, these hypotheses cannot be evaluated in this meta-analysis.

This meta-analysis had some limitations. First, it included only articles from three databases (Scielo, Pubmed and Scopus). This can lead to no identification of minor or locally published studies, whose inclusion could alter some of the findings presented herein (such as TOF being equally prevalent among genders in DS). Second, the populations included in this paper are rather different among themselves. For example, Morris et al. included data from 20 European Countries, and of both live births and abortions after the 20th week [25]. It is known that the prevalence of CHD, particularly complex malformations, is higher in abortions [39]. Conversely, Pinto et al. and Jaiyesimi et al. included children followed in health centers, which can overestimate the prevalence of CHD [22, 24]. Vis et al. included only adults with DS, which can reduce the prevalence of complex heart diseases (due to higher mortality) [23]. Third, it was not possible to perform an analysis of ethnicity separated by gender, which could provide more insights on the origin of CHD in DS. Despite such limitations, however, it was possible to show a clear trend of a higher prevalence of CHD (more specifically of AVSD) in the female population with DS.

\section{Conclusion}

This brief meta-analysis demonstrated higher prevalence of congenital heart disease, particularly AVSD, on female patients with Down syndrome.

\section{Additional files}

Additional file 1: Search strategy in Pubmed. Contains the terms and strategy to find the main articles of this meta-analysis in Pubmed. (DOC $51 \mathrm{~kb}$ )

Additional file 2: Raw data. Contains the raw data obtained from the articles for congenital heart disease and Down syndrome prevalence by gender. (DOCX $11 \mathrm{~kb}$ )

\section{Abbreviations}

ASD: Atrial septal defects; AVSD: Atrioventricular septal defects; CHD: Congenital heart disease; CNV: Copy number variations;

Decs: Descriptors of Health Sciences; DS: Down's syndrome; OR: Odds ratio; PDA: Patent ductus arteriosus; SNPs: Single-nucleotide polymorphism; TOF: Tetralogy of fallot; VSD: Ventricular septal defects

\section{Acknowledgements}

Not applicable

Funding

None

Availability of data and materials

The articles included in this meta-analysis can be found in the respective journals. More information at the bibliography section. The raw data is included in the Additional file 2 .

\section{Authors' contributions}

FM carried out the statistical analysis and part of the articles selection. SM carried out part of the articles selection and revised the manuscript critically for important intellectual content. TD participated in the design of the study and drafted the manuscript. JF revised the manuscript critically for important intellectual content and participated in its design and coordination. All authors read and approved the final manuscript.

Ethics approval and consent to participate

Not applicable

Consent for publication

Not applicable

\section{Competing interests}

The authors declares that there is no conflict of interest regarding the publication of this paper.

\section{Publisher's Note}

Springer Nature remains neutral with regard to jurisdictional claims in published maps and institutional affiliations.

\section{Author details}

${ }^{1}$ Círculo do Coração de Pernambuco, Recife, Pernambuco, Brazil.

${ }^{2}$ Universidade Federal de Pernambuco (UFPE), Recife, Pernambuco, Brazil.

${ }^{3}$ Unidade de Cardiologia Materno e Fetal (UCMF), Av. Governador

Agamenon Magalhães, 4760, Paissandu, PE CEP 52010-902, Brazil. 
Received: 13 June 2017 Accepted: 3 October 2017

Published online: 06 October 2017

\section{References}

1. Nadal M, Moreno S, Pritchard M, Preciado MA, Estivill X, Ramos-Arroyo MA. Down syndrome: characterisation of a case with partial trisomy of chromosome 21 owing to a paternal balanced translocation (15;21) (q26;q22.1) by FISH. J Med Genet. 1997;34:50-4.

2. Cuckle HS. Primary prevention of Down's syndrome. Int J Med Sci. 2005;2(3): 93-9.

3. Vilas Boas LT, Albernaz EP, Costa RG. Prevalence of congenital heart defects in patients with down syndrome in the municipality of Pelotas. Brazil J Pediatr (Rio J). 2009;85:403-7.

4. Laursen HB. Congenital heart disease in Down's syndrome. Br Heart J. 1976;38:32-8

5. Li H, Cherry S, Klinedinst D, DeLeon V, Redig J, Reshey B, et al. Genetic modifiers predisposing to congenital heart disease in the sensitized down syndrome population. Circ Cardiovasc Genet. 2012;5:301-8.

6. Mikkelsen $M$, Poulsen $H$, Nielsen KG. Incidence, survival, and mortality in down syndrome in Denmark. Am J Med Genet Suppl. 1990;7:75-8.

7. Tubman TR, Shields MD, Craig BG, Mulholland HC, Nevin NC. Congenital heart disease in Down's syndrome: two year prospective early screening study. BMJ Br Med J. 1991;302:1425-7.

8. Alabdulgader AAA. Congenital heart disease in 740 subjects: epidemiological aspects. Ann Trop Paediatr. 2001;21:111-8.

9. Nisli K, Oner N, Candan S, Kayserili H, Tansel T, Tireli E, et al. Congenita heart disease in children with Down's syndrome: Turkish experience of 13 years. Acta Cardiol. 2008:63:585-9.

10. Hartman RJ, Rasmussen SA, Botto LD, Riehle-Colarusso T, Martin CL, Cragan JD, et al. The contribution of chromosomal abnormalities to congenital heart defects: a population-based study. Pediatr Cardiol. 2011;32:1147-57.

11. Al-Jarallah AS. Down's syndrome and the pattern of congenital heart disease in a community with high parental consanguinity. Med Sci Monit. 2009;15:CR409-12.

12. Bermudez BEBV, Medeiros SL, Bermudez MB, Novadzki IM, Magdalena NIR. Down syndrome: prevalence and distribution of congenital heart disease in Brazil. São Paulo Med J. 2015;133:521-4

13. Scott $C$, Thame $M$. The incidence of cardiac lesion among children with Down's syndrome in Jamaica - a prospective study. West Indian Med J. 2014;63(7):693-7.

14. Başpinar O, Karaaslan S, Oran B, Baysal T, Elmaci AM, Yorulmaz A. Prevalence and distribution of children with congenital heart diseases in the central Anatolian region. Turkey Turk J Pediatr. 2006;48:237-43.

15. Locke AE, Dooley K, Tinker SW, Cheong SY, Feingold E, Allen EG, et al. Variation in folate pathway genes contributes to risk of congenital heart defects among individuals with down syndrome. Genet Epidemiol. 2010;34:613-23.

16. Liu C, Morishima M, Yu T, Matsui S-I, Zhang L, Fu D, et al. Genetic analysis of down syndrome-associated heart defects in mice. Hum Genet. 2011;130:623-32.

17. Ackerman C, Locke AE, Feingold E, Reshey B, Espana K, Thusberg J, et al. An excess of deleterious variants in VEGF-A pathway genes in down-syndromeassociated atrioventricular septal defects. Am J Hum Genet. The American Society of Human Genetics. 2012;91:646-59.

18. Sailani MR, Makrythanasis P, Valsesia A, Santoni FA, Deutsch S, Popadin K, et al. The complex SNP and CNV genetic architecture of the increased risk of congenital heart defects in down syndrome. Genome Res. 2013;23:1410-21.

19. Ramachandran D, Zeng Z, Locke AE, Mulle JG, Bean LJH, Rosser TC, et al. Genome-wide association study of down syndrome-associated Atrioventricular Septal defects. G3 (Bethesda). 2015;5:1961-71.

20. Freeman SB, Bean LH, Allen EG, Tinker SW, Locke AE, Druschel C, et al. Ethnicity, sex, and the incidence of congenital heart defects: a report from the National down Syndrome Project. Genet Med. 2008;10:173-80.

21. Mourato FA, Villachan LRR. Mattos $S$ da S. Prevalence and profile of congenital heart disease and pulmonary hypertension in down syndrome in a pediatric cardiology service. Rev. Paul. Pediatr. 2014;32:159-63.

22. Pinto FF, Nunes L, Ferraz F, Sampayo F. Down's syndrome: different distribution of congenital heart diseases between the sexes. Int J Cardiol. 1990;27:175-8.

23. Vis JC, de Bruin-Bon RH, Bouma BJ, Huisman S, Imschoot L, van den Brink K, et al. Congenital heart defects are under-recognised in adult patients with Down's syndrome. Heart. 2010;96:1480-4.

24. Jaiyesimi O, Baichoo V. Cardiovascular malformations in Omani Arab children with Down's syndrome. Cardiol Young. 2007;17:166-71.
25. Morris JK, Garne E, Wellesley D, Addor MC, Arriola L, Barisic I, et al. Major congenital anomalies in babies born with down syndrome: a EUROCAT population-based registry study. Am J Med Genet Part A. 2014;164:2979-86.

26. Kim MA, Lee YS, Yee NH, Choi JS, Choi JY, Seo K. Prevalence of congenital heart defects associated with down syndrome in Korea. J Korean Med Sci. 2014:29:1544-9.

27. Vida VL, Barnoya J, Larrazabal LA, Gaitan G, de Marian GF, Castaneda AR. Congenital cardiac disease in children with Down's syndrome in Guatemala. Cardiol Young. 2005;15:286-90.

28. Bergstrom S, Carr H, Petersson G, Stephansson O, Bonamy A-KE, Dahlstrom $A$, et al. Trends in congenital heart defects in infants with down syndrome. Pediatrics. 2016;138(1):1-9.

29. Narayanan DL, Yesodharan D, Kappanayil M, Kuthiroly S, Thampi MV, Hamza Z, et al. Cardiac spectrum, cytogenetic analysis and thyroid profile of 418 children with down syndrome from South India: a cross-sectional study. Indian J Pediatr. 2014;81:547-51.

30. Källén B, Mastroiacovo P, Robert E. Major congenital malformations in down syndrome. Am J Med Genet. 1996;65:160-6.

31. De Rubens Figueroa J, Mangana BP, JLP H, Jiménez CC, Urbina RC. Hearth malformations in children with down syndrome. Rev Esp Cardiol. 2003:56:894-9.

32. Elmagrpy Z, Rayani A, Shah A, Habas E, Aburawi EH. Down syndrome and congenital heart disease : why the regional difference as observed in the Libyan experience? Cardiovasc J Afr. 2011;22:306-9.

33. Espinola-Zavaleta N, Soto ME, Romero-Gonzalez A, Gómez-Puente LDC, Muñoz-Castellanos L, Gopal AS, et al. Prevalence of congenital heart disease and pulmonary hypertension in down's syndrome: an echocardiographic study. J Cardiovasc Ultrasound. 2015;23:72-7.

34. Grech V, Gatt M. Syndromes and malformations associated with congenital heart disease in a population-based study. Int J Cardiol. 1999;68:151-6.

35. Irvine B, Luo W, Leo JA. Congenital anomalies in Canada 2013: a Perinatal health surveillance report by the Public Health Agency of Canada's Canadian Perinatal surveillance system. Heal Promot Chronic Dis Prev Canada. 2015:35:2013-4

36. Robinson SW, Morris CD, Goldmuntz E, Reller MD, Jones MA, Steiner RD, et al. Missense mutations in CRELD1 are associated with cardiac atrioventricular septal defects. Am J Hum Genet. 2003;72:1047-52.

37. Pierpont ME, Basson CT, Benson DW, Gelb BD, Giglia TM, Goldmuntz E, et al. Genetic basis for congenital heart defects: current knowledge: a scientific statement from the American Heart Association congenital cardiac defects committee, council on cardiovascular disease in the young: endorsed by the American Academy of Pediatrics. Circulation. 2007;115:3015-38.

38. Croti U, Mattos S, Pinto V Jr, Aiello V, Moreira V. Genética das Cardiopatias Congênitas. Cardiol. e Cir. Cardiovasc. pediátrica. 20. São Paulo: Roca; 2012. p. 47-56.

39. Stoll C, Alembik Y, Dott B, Roth MP. Study of down syndrome in 238,942 consecutive births. Ann génétique. 1998:41:44-51.

\section{Submit your next manuscript to BioMed Central and we will help you at every step:}

- We accept pre-submission inquiries

- Our selector tool helps you to find the most relevant journal

- We provide round the clock customer support

- Convenient online submission

- Thorough peer review

- Inclusion in PubMed and all major indexing services

- Maximum visibility for your research

Submit your manuscript at www.biomedcentral.com/submit
) Biomed Central 